\title{
Rheumatic Heart Disease in Nepal: Current Scenario
}

\author{
Man Bahadur KC
}

Department of Cardiology, Shahid Gangalal National Heart Centre, Bansbari, Kathmandu, Nepal Corresponding Author: Man Bahadur KC, Department of Cardiology, Shahid Gangalal National Heart Centre, Bansbari Kathmandu, Nepal,

Email: manbdrkc@yahoo.com

\begin{abstract}
Rheumatic Heart Disease, though declining in developed world, is still prevalent in Nepal in spite of increased awareness and improvement in preventive programs. This article presents the current scenario of Rheumatic Heart Disease in Nepal.
\end{abstract}

Keywords : Acute Rheumatic Fever ; Rheumatic Heart Disease; Prevalence;

\section{Introduction}

Rheumatic Heart Disease (RHD) is the most common acquired heart disease in children in developing countries. ${ }^{1}$ RHD is a chronic heart condition caused by acute rheumatic fever (ARF) which can be prevented and controlled. ARF is caused by a preceding group A Streptococcal infection. Treatment of Streptococcal throat/ear infection with antibiotics can prevent ARF. Like in other developing countries, RHD continues to be an important public health problem in Nepal. Thousands of deaths in children and young adults annually are attributed to RHD in Nepal.

\section{Epidemiology and Burden of Disease}

A number of studies have attempted to document prevalence of RHD in Nepal. Most of these prospective surveys have been carried out either in schools or in school aged children in communities. The limitations of these studies are that they fail to include seriously ill children and older individuals with RHD. (Table 1)
Lack of systematic survey is a major limitation in the estimation of disease burden in Nepal. Shrestha UK, et al. for the first time, published the prevalence of RHD in children of rural area. Subsequently few more studies were published on prevalence of RHD in Nepal in various national and international journals. ${ }^{2,3,4,5,6}$ All these studies showed the prevalence of RHD among school children to be between 0.91.35 per thousand. Only in the study done by Shrestha NR, et al. ${ }^{6}$ showed the prevalence of RHD too high but this study was done with the echocardiography study in all the children. The actual magnitude of the problem might be more than what is reflected in these studies as rural population was not included and RHD is more prevalent in this population. RHD is among the top three reasons for admission in cardiology department and also second most common cause of cardiac surgery at Shahid Gangalal National Heart Center (SGNHC), ${ }^{7}$ a government owned tertiary cardiac centre in Kathmandu as shown in Table 2, 3 .

\begin{tabular}{|c|c|c|c|c|c|c|}
\hline & Study & Year & Study Area & $\begin{array}{l}\text { Total Children } \\
\text { screened }\end{array}$ & $\begin{array}{l}\text { Prevalance of RHD } \\
\text { (per thousand) }\end{array}$ & Study age group \\
\hline 1 & Shrestha UK, et $\mathrm{al}^{2}$ & 1991 & Rural Nepal & 4452 & 1.35 & 5-16years \\
\hline 2 & Regmi PR, et al ${ }^{3}$ & 1996 & Kathmandu & 4736 & 1.2 & $5-16$ years \\
\hline 3 & $\mathrm{KC} \mathrm{MB}$, et $\mathrm{al}^{4}$ & 2002 & Kathmandu & 9420 & 1.2 & 5 -18years \\
\hline 4 & Prajapati D, et $\mathrm{al}^{5}$ & 2013 & Kathmandu & 34,876 & 0.9 & $5-15$ years \\
\hline 5 & Shrestha NR, et al ${ }^{6}$ & 2015 & Sunsari & 5,178 (Echo based) & 10.2 & $5-15$ years \\
\hline
\end{tabular}


Table 2. Top 3 reasons for admission in SGNHC

\begin{tabular}{|c|c|c|c|c|c|}
\hline Year & $2011(\%)$ & $2012(\%)$ & $2013(\%)$ & $2014(\%)$ & $2015(\%)$ \\
\hline 1 & CAD (37.4) & CAD (38.0) & CAD $(49.5$ & CAD (44.6) & $\mathrm{CAD}(45.4)$ \\
\hline 2 & HTN (18.5) & HTN (14.0) & DCM (10.5) & DCM (13.6) & HTN (15.8) \\
\hline 3 & RHD (14.5) & RHD (14.0) & RHD (10.4) & RHD (8.8) & RHD (6.0) \\
\hline
\end{tabular}

Table 3. Total number of valve surgeries associated with RHD in SGNHC

\begin{tabular}{lllllllll} 
Year & $\mathbf{2 0 0 9}$ & $\mathbf{2 0 1 0}$ & $\mathbf{2 0 1 1}$ & $\mathbf{2 0 1 2}$ & $\mathbf{2 0 1 3}$ & $\mathbf{2 0 1 4}$ & $\mathbf{2 0 1 5}$ \\
\hline Surgeries & 507 & 451 & 459 & 390 & 517 & 520 & 499 \\
\hline$\%$ & 36 & 32 & 31.2 & 29.1 & 37.2 & 34 & 35 &
\end{tabular}

\section{Treatment Facilities}

As already mentioned, RHD is among the top three reasons for admission in cardiology department and second reason for cardiac surgery at SGNHC, the center regularly performs percutaneous transseptal mitral commissurotomy (PTMC), mitral and tricuspid valve repair, and valve replacement surgeries. Number of PTMC and valve surgery done at SGNHC has not declined over the years as shown in Table 3 and 4. Manmohan cardiothoracic vascular and Transplant Centre, another government owned university hospital regularly performs valve repair and replacement surgeries. Limited treatment facilities are available in other centers like BP Koirala Institute of Health sciences, Bir Hospital, Dhulikhel Hospital, Norvic International Hospital, Grande Hospital, Vayodha Hospital and Chitwan Medical College.

\section{Government Initiatives in Treatment of RHD}

The treatment of RHD is expensive, majority of Nepalese population are unable to afford the treatment. Government of Nepal has been providing free of cost surgeries for children under 15, adults over 75 and free PTMC for all population. It also provides financial assistance to the needy patients who need valve surgery. Government of Nepal also provides 200 free valves for poor patient in SGNHC and 100 valves for Manmohan Cardiothoracic Vascular and Transplant Centre.

\section{Conclusion}

The diagnosis and treatment of RHD has improved but the RHD still remains a major cardiovascular disease in Nepal. Lack of large registry and health facilities in rural part of Nepal still poses a major obstacle. Improvement in awareness, prompt diagnosis, primary and secondary prevention remains the important issue for decline in incidence of RHD.

\section{Table 4. Total Number of PTMC}

\begin{tabular}{|llllllll}
\hline Year & 2009 & 2010 & 2011 & 2012 & 2013 & 2014 & 2015 \\
\hline No & 400 & 407 & 366 & 475 & 403 & 328 & 422 \\
\hline
\end{tabular}

\section{References:}

1. Mendis S, Puska P, Norrving B. Global Atlas as Cardiovascular Disease Prevention and control. World Health Organization [in collaboration with the World Heart Federation and World Stroke Organization], Geneva 2011.

2. Shrestha U K, Bhattarai T.N, Pandey M R. Prevalence of Rheumatic fever and Rheumatic heart Disease in school children in a rural community of the Hill Region of Nepal. Indian heart J.1991;43(1):39-41.

3. Regmi P R, Pandey M R. Prevalence of rheumatic fever and rheumatic heart disease in school children of Kathmandu city. Indian heart J. 1997; 49 : 518-41.

Cite this article as: Man Bahadur KC. Rheumatic Heart Disease in Nepal: Current Scenario. Nepalese Heart Journal 2016;13(2): $1-2$.
4. K C MB, Sharma D, Shrestha M P at al. Prevalence of Rheumatic and Congenital heart Disease in school children of Kathmandu Valley in Nepal. Indian heart J. 2002: 55: 615-618.

5. Prajapati D, Sharma D, Regmi P.R, et al. Epidemiologocal survey on Rheumatic fever, Rheumatic heart Disease and Congenital Heart Disease among school children in Kathmandu Valley of Nepal. Nepalese heart Journal 2013; 10(1): 1-5.

6. Shrestha N R, Karki P, Mahato R at al, Prevalance of sub clinical. Rheumatic heart Disease in Eastern Nepal. JAMA Cardiol 2016;1(1):89-96.

7. Annual Report of Shahid Gnagalal National Heart Centre (2009, 2010, 2011, 2012, 2013, 2014, 2015). 